\title{
Validation of the Chinese Version of the Shame and Stigma Scale in Patients with Head and Neck Cancer
}

This article was published in the following Dove Press journal: Cancer Management and Research

\author{
Wei-Ting Tseng (1D) \\ Yu Lee' \\ Chi-Fa Hung' \\ Pao-Yen Lin (D) \\ Chih-Yen Chien (D) $^{2}$ \\ Hui-Ching Chuang ${ }^{2}$ \\ Fu-Min Fang ${ }^{3}$ \\ Shau-Hsuan $\mathrm{Li}^{4}$ \\ Tai-Lin Huang ${ }^{4}$ \\ Mian-Yoon Chong ${ }^{5}$ \\ Liang-Jen Wang $\mathbb{1 D}^{6}$
}

'Department of Psychiatry, Kaohsiung Chang Gung Memorial Hospital and Chang

Gung University College of Medicine,

Kaohsiung, Taiwan; ${ }^{2}$ Department of

Otolaryngology, Kaohsiung Chang Gung

Memorial Hospital and Chang Gung

University College of Medicine, Kaohsiung,

Taiwan; ${ }^{3}$ Department of Radiation

Oncology, Kaohsiung Chang Gung

Memorial Hospital, Chang Gung University

College of Medicine, Kaohsiung, Taiwan;

${ }^{4}$ Department of Hematology-Oncology,

Kaohsiung Chang Gung Memorial Hospital and Chang Gung University College of

Medicine, Kaohsiung, Taiwan; ${ }^{5}$ Department of Psychiatry, Chiayi Chang Gung Memorial Hospital and Chang Gung University

College of Medicine, Chiayi, Taiwan;

${ }^{6}$ Department of Child and Adolescent

Psychiatry, Kaohsiung Chang Gung

Memorial Hospital and Chang Gung

University College of Medicine, Kaohsiung,

Taiwan

Correspondence: Liang-Jen Wang

Department of Child and Adolescent

Psychiatry, Kaohsiung Chang Gung

Memorial Hospital, No.123, Dapi Road,

Niaosung District, Kaohsiung City, Taiwan

Tel +886-7-73I7| 23 ext. 8753

Fax +886-7-7326817

Email wangliangjen@gmail.com
Purpose: Head and neck cancer (HNC) patients suffer from perceived shame and stigma due to the illness diagnosis, as well as disfigurement following surgery. To measure HNC patients' perception of shame and stigma, the Shame and Stigma Scale (SSS) was developed and preliminarily validated. In this study, we aimed to translate, adapt, and validate the SSS in Chinese.

Methods: This study consisted of a cross-sectional design with consecutive sampling and consisted of two stages: (1) translation of the SSS into Chinese by two bilingual professionals and (2) examination of the Chinese version of the SSS (C-SSS) for internal consistency, inter-rater reliability, test-retest reliability, construct validity, and concurrent validity. In total, 159 inpatients with HNC (mean age: 56.8 years, 95\% males) were enrolled at a medical center in Southern Taiwan.

Results: The Principal Component Analysis of the C-SSS revealed a five-factor structure: 4 of the 5 factors were replicated in the original SSS, including Shame with Appearance, Regret, Social/Speech Concern, and Sense of Stigma; only factor 4, Self-discrimination, was newly identified in the current study. C-SSS showed acceptable internal validity (Cronbach's $\alpha=0.85$ ), test-retest reliability, inter-rater reliability, and fair concurrent validity with the Taiwanese Depression Questionnaire (TDQ), Hamilton Depression Rating Scale (HAM-D), Hamilton Anxiety Rating Scale (HAM-A), and Explanatory Model Interview Catalogue (EMIC).

Conclusion: The findings of this study indicate that C-SSS is a reliable and valid instrument for evaluating HNC patients' perception of shame and stigma in the Taiwanese population. Keywords: head and neck cancer, shame, stigma, assessment, psychometric

\section{Introduction}

Cancer has been among the leading cause of death around the world for decades. Head and neck cancer (HNC) includes cancers of the oral cavity, oropharynx, hypopharynx, and larynx. The world's highest incidence rates of oral cavity and lip cancers tend to be focused in South Asia, including Taiwan. ${ }^{1}$ In 2016, oral cavity cancer ranked sixth for incidence and fifth for mortality in Taiwan, accounting for $7.37 \%$ (7805 cases) of all new cancers diagnosed and 6.15\% (2936 deaths) of all cancer deaths. ${ }^{2}$

The risk factors that contribute to $\mathrm{HNC}$ include tobacco use, alcohol consumption, human papilloma virus (HPV) positivity, and in some regions in Asia, like Taiwan, the habit of chewing betel quid. ${ }^{3,4}$ Such known behavioral risk factors 
construct the public's negative impression and are related to the stigmatization of people diagnosed with $\mathrm{HNC}$ in social and cultural contexts.

Previous studies have shown that HNC patients are often comorbid with depressive disorders. Approximately $40 \%$ of patients develop depression during HNC diagnosis and treatment. ${ }^{5} \mathrm{~A}$ meta-analysis study reported that the prevalence of depression in patients with $\mathrm{HNC}$ was $11 \%$ based on diagnostic interviews and $20 \%$ based on selfreported instruments. ${ }^{6}$ Depression affects HNC patients' quality of life, nutritional status, and survival outcomes. ${ }^{7}$ Cancer patients suffering from mental illness may opt not to seek medical care in order to avoid "public stigma," further labelling themselves as the "mentally ill" minority. ${ }^{8}$

Cancer is a highly stigmatized illness, and such stigma affects patients' help-seeking intention and behaviors, consequently leading to delayed diagnosis and treatment. ${ }^{9}$ Taiwan's high incidence of HNC was considered to be associated with patterns of cigarette smoking and betel quid chewing habits in the island's cultural background. ${ }^{10}$ Previous qualitative and exploratory studies have identified various psychosocial issues surrounding the concept of shame and stigma in patients with HNC, including shame, disfigurement after surgery, body-image change, social identity, social isolation, regret, and guilt. ${ }^{11-14}$ Facial disfigurement following treatment impacts depression and the quality of life of patients and their partners. ${ }^{11,15,16}$

In order to objectively measure HNC patients' perceptions of shame and stigma, a 20-item Shame and Stigma Scale (SSS) was developed by Kissane et $\mathrm{al}^{17}$ in the US Items were administered to 104 patients with squamous cell carcinoma in the oral cavity at Memorial SloanKettering Cancer Center in New York, together with measures of quality of life and adaptation. The psychometric properties were tested to construct a four-factor model (shame of appearance, sense of stigma, regret, and speech/social concerns) with a satisfactory internal validity (Cronbach's alpha of 0.94).$^{17}$ The SSS was also translated and culturally adapted into a Portuguese version in Brazil, ${ }^{18}$ but the scale has not yet been translated and applied in any Chinese-speaking areas.

A reliable and valid tool for measuring shame and stigma of HNC patients in the Chinese language is lacking, which limits the ability to assess stigma and development intervention methods to reduce public stigma. Therefore, the aims of this study were to translate, adapt, and validate SSS in the Chinese language spoken in Taiwan.

\section{Materials and Methods}

\section{Study Design and Participants}

All procedures performed in studies involving human participants were in accordance with the Declaration of Helsinki (1964) and its later amendments or comparable ethical standards. The Institutional Review Board at Chang Gung Memorial Hospital has approved this study (IRB no: 201601843A3C501).

This study used a cross-sectional design with consecutive sampling and consisted of two stages: (1) adaptation of the original English version of the Shame and Stigma Scale (SSS) into Chinese (through translation and backtranslation) and (2) examination of the Chinese version of the SSS (C-SSS) for internal consistency, inter-rater reliability, test-retest reliability, construct validity, and concurrent validity. We recruited participants from the ENT inpatient department at a tertiary hospital from March 2018 to February 2019. This hospital has 2754 beds and annually provides services to 5000 cancer patients in southern Taiwan. The inclusion criteria were as follows: (1) patients diagnosed with HNC by biopsy or surgical resection (newly diagnosed or relapsed); (2) patients with the ability to comprehend the questionnaires and could express themselves by speech or writing. The exclusion criteria consisted of the following: (1) patients with a history of prior cancer other than HNC; (2) patients with dementia or severe cognitive impairment; (3) patients too weak to complete the questionnaire or clinical interview.

\section{Assessments}

\section{Shame and Stigma Scale (SSS)}

The SSS is an instrument for evaluating the sense of shame and stigma reported by patients, which was developed among 104 patients with oral cavity cancer by Dr. David Kissane in 2013 in the United States. ${ }^{17}$ The SSS consists of 20 items with a strong internal consistency (Cronbach's alpha was 0.94) and the following four factors: shame of appearance, sense of stigma, regret, and speech/social concerns, with a satisfactory internal validity.

\section{Taiwanese Depression Questionnaire (TDQ)}

The TDQ is a culturally sensitive self-reported instrument for screening depression in Taiwan. ${ }^{19}$ This questionnaire is composed of 18 items related to mood, sleeping problems, appetite, energy, interest in normal activities, crying, and feelings about the future. The participants were asked to indicate whether each item has been experienced and how frequently on a 4-point Likert scale (ranging from 0 to 3). 
The TDQ had satisfactory reliability and validity in a community study and among patients with chronic pain. ${ }^{19,20}$ We also completed a study examining the validity of the TDQ for detecting depression in cancer patients, which resulted in a satisfactory validity index. ${ }^{21}$

\section{Hamilton Depression Rating Scale (HAM-D)}

The Hamilton Depression Rating Scale (HAM-D) has been widely used to assess the severity of depression but has been criticized for its over-emphasis on neurovegetative symptoms. ${ }^{22}$ HAM-D was designed to be researcher-administered by probing a subject's mood, feelings of guilt, suicide ideation, insomnia, agitation or retardation, anxiety, weight loss, and somatic symptoms. It takes 15 to 20 mins for researchers to complete this questionnaire. $^{22}$ The reliability and validity of the Chinese version of the 17-item HAM-D has been proven, and thus it can be used in clinical and research settings. ${ }^{23}$

\section{Hamilton Anxiety Rating Scale (HAM-A)}

The Hamilton Anxiety Rating Scale (HAM-A) is among the first and most widely used rating scales to measure the severity of perceived anxiety symptoms. ${ }^{24}$ The HAM-A, a clinician-based questionnaire, consists of 14 symptomdefined elements, including both psychological and somatic symptoms. Each item is scored on a basic numeric scoring of 0 (not present) to 4 (severe): $>17$ is taken to indicate mild anxiety; $25-30$ is considered moderatesevere. $^{24}$ One study examined the HAM-A's reliability and validity and concluded that its inter-rater reliability, one-week test-retest reliability, and concurrent validity were satisfactory. ${ }^{25}$

\section{Explanatory Model Interview Catalogue (EMIC)}

The Explanatory Model Interview Catalogue (EMIC), an anthropologically based semi-structured interview schedule, systematically examines patients' help-seeking behavior through quantitative and qualitative data information. ${ }^{26}$ EMIC has been used as a study instrument and widely applied in the field of cultural psychiatry, which has focused on patients' illness behavior and stigma over the past 20 years. $^{27-29}$

\section{Procedures}

Ethical approval was obtained from the human research ethics committee of Chang Gung Memorial Hospital. The study procedures were as follows: (1) Translation and adaptation: First, three translators translated the SSS into Chinese. The three translators were the authors, Dr. Yu
Lee, Dr. Chi-Fa Hung and Prof. Liang-Jen Wang, who are all specialized in psychiatry and fluent in both Chinese and English. After discussion, three versions of translated SSS were synthesized into a unified Chinese version after reaching an agreement. To check the accuracy, this Chinese version was translated back into English by an English professor, Chih-Hsien Hsieh, who has a $\mathrm{PhD}$ and specializes in translation and English literature. He lacked medical background and had no prior knowledge of the original version of SSS. To establish expert validity, we consulted Prof. Cheng-Fang Yen and Prof. Cheng-Chung Chen, both of them are senior psychiatrists and experts in this field. Finally, The C-SSS was reviewed and approved by Dr. Kissane, until the back-translation was sufficiently similar to the original version in order to reach conceptual consistency. The finalized Chinese version of SSS was supplemented (Supplementary Table 1). We obtained the copyright permission from Dr. Kissane to reproduce the SSS items herein.

Furthermore, we documented the participants' qualitative descriptions while answering the SSS questionnaire, which contributed to making any necessary modifications. (2) Newly-diagnosed patients admitted to our ward were subsequently invited to take part in this study. Once our research assistant received a referral from the outpatient clinic or wards from in-charge doctors or case managers, our research assistant visited the above settings to contact patients. After explaining the study procedures and aims, those who agreed to participate signed an informed consent form and were enrolled in the study. (3) A senior psychiatrist (Dr. Y. Lee) made the psychiatric diagnoses using the MINI, HAM-A, and HAM-D. (4) The C-SSS, TDQ, and clinical and demographic data were collected by a trained research assistant. (4) A psychiatrist (Dr. Tseng) conducted C-SSS with our research assistant to examine the inter-rater reliability.

\section{Statistical Analyses}

Descriptive statistics were used to characterize the sociodemographic data by gender, age, educational level, marital status, occupation, cancer site and stage, alcohol use, betel nut chewing habit, suicide history, and psychiatric disorder history. Furthermore, the Chi-squared test was used to analyze group differences. The factor structure was extracted by performing a principal component analysis using a Varimax rotation. We assessed the internal consistency reliability of the C-SSS using Cronbach's $\alpha$ coefficient, where $\alpha \geq 0.70$ was considered satisfactory. ${ }^{30}$ 
Fifty participants completed the questionnaires at an interval of 1-2 weeks by two administrations. We examined test-retest reliability (repeatability) and inter-rater analysis by calculating the intra-class correlation coefficient (ICC). ${ }^{31}$ The concurrent validity between the C-SSS and other measures (TDQ, HAMD, HAMA, and EMIC) were assessed using Pearson product moment correlations. All analyses were conducted using the Statistical Package for the Social Sciences (SPSS) software, version 12.

\section{Results}

\section{Sociodemographic Features of}

\section{Participants}

We initially recruited 178 patients for this study, but 19 patients did not complete the study due to resistance or refusal, $15 / 166(9.03 \%)$ in male and $4 / 12(33.33 \%)$ in female. In total, we successfully achieved the data collection of 159 patients (the response rate was $88.1 \%$ ). Among the 159 subjects that successfully completed the study, $95.0 \%(\mathrm{n}=151)$ were males. The average age of subjects was $56.8( \pm 9.3)$ years. Their mean educational level was $10.3( \pm 3.2)$ years, $66.7 \%$ were married, and $47.2 \%$ were currently unemployed. Sixty-three percent of the patients had advanced (stage III and IV) disease. Oral cavity cancer (59.7\%) was the most common cancer site among our HNC patients. Surgery (57.2\%) was the most commonly used treatment modality among our patients. Substance use data showed that $88.7 \%$ of those patients with HNC had smocked tobacco, $83.6 \%$ of patients had betel nut chewing habit, and $80.9 \%$ of patients had an alcohol drinking habit. One-fifth of our HNC patients had a past history of psychiatric disorder (Table 1).

\section{Construct Validity}

The factor loadings were extracted from the polychoric correlation matrix of the items by using principal component analysis with a varimax rotation. Factor loadings in bold print indicate the subscale on which the item was scored. A fivefactor solution best fit the 20 items (Table 2), accounting for $60.0 \%$ of the total variance of the items, which is satisfactory. ${ }^{32}$ Factor 1 captured shame of appearance (items 1, 2, 3, 4, 5, 6, 8, 14); factor 2, regret about past behaviors, (items 15, 16, 17); factor 3, social and speech concerns (items 18, 19, 20); factor 4, self-discrimination (items 9, 10, 13); and factor 5, sense of stigma (items 7, 11, 12). This result indicates that the C-SSS has satisfactory
Table I Sociodemographic and Clinical Characteristics of Participants $(n=159)$

\begin{tabular}{|c|c|}
\hline Characteristic & $\begin{array}{l}\mathbf{N}(\%) \text { or } \\
\text { Mean } \pm S D\end{array}$ \\
\hline \multicolumn{2}{|l|}{ Gender } \\
\hline Male & $|5|(95.0)$ \\
\hline Female & $8(5.0)$ \\
\hline Age & $56.8 \pm 9.3$ \\
\hline \multicolumn{2}{|l|}{ Education } \\
\hline Under elementary school $(\leq 6)$ & $24(15.1)$ \\
\hline High school $(\leq 12)$ & $122(76.7)$ \\
\hline Over college $(>12)$ & $13(8.2)$ \\
\hline Education years & $10.3 \pm 3.2$ \\
\hline \multicolumn{2}{|l|}{ Marital status } \\
\hline Unmarried & $53(33.3)$ \\
\hline Married & $106(66.7)$ \\
\hline Unemployment & $75(47.2)$ \\
\hline \multicolumn{2}{|l|}{ Occupation } \\
\hline House keeper & $5(3.1)$ \\
\hline Agriculture & $10(6.3)$ \\
\hline Constructions and manufacturing & $39(24.5)$ \\
\hline $\begin{array}{l}\text { Public administration, active duty military and } \\
\text { educational services }\end{array}$ & $2(1.3)$ \\
\hline Business & $14(8.8)$ \\
\hline Others & $17(10.7)$ \\
\hline VAS & $2.8 \pm 2.7$ \\
\hline \multicolumn{2}{|l|}{ Cancer } \\
\hline Oral cavity cancer & $95(59.7)$ \\
\hline Oropharyngeal cancer & $28(17.6)$ \\
\hline Hypopharyngeal Cancer & $18(\mid 1.3)$ \\
\hline Laryngeal cancer & $16(10.1)$ \\
\hline Salivary gland cancer & $2(1.3)$ \\
\hline \multicolumn{2}{|l|}{ Stage } \\
\hline Early & $58(37.1)$ \\
\hline Advanced & $97(62.6)$ \\
\hline \multicolumn{2}{|l|}{ Treatment } \\
\hline Operation & $91(57.2)$ \\
\hline Chemotherapy & $5(3.1)$ \\
\hline Radiotherapy & $2(1.3)$ \\
\hline Others & $\mathrm{I}(\mathrm{I} .3)$ \\
\hline Combined treatment & $59(37.1)$ \\
\hline Alcohol use & $128(80.9)$ \\
\hline Smoking tobacco & $|4|(88.7)$ \\
\hline Betel-nuts chewing & $133(83.6)$ \\
\hline Suicide history & $6(3.8)$ \\
\hline
\end{tabular}

(Continued) 
Table I (Continued).

\begin{tabular}{|l|l|}
\hline Characteristic & $\begin{array}{l}\text { N (\%) or } \\
\text { Mean } \pm \text { SD }\end{array}$ \\
\hline Psychiatric diagnosis & \\
Alcohol dependence & $42(26.4)$ \\
Major depressive disorder & $24(15.1)$ \\
Depressive disorder NOS & $23(14.5)$ \\
Adjustment disorder & $22(13.8)$ \\
Insomnia disorder & $13(8.2)$ \\
Dysthymia & $5(3.2)$ \\
Bipolar II disorder & $\mathrm{I}(0.6)$ \\
No psychiatric disorder & $48(30.2)$ \\
\hline
\end{tabular}

construct validity. This result is similar to the original factor analysis of SSS, except that another factor, selfdiscrimination, is added.

\section{Concurrent Validity}

We performed Pearson product moment correlations of the C-SSS scale and subscales with TDQ, HAM-D, HAM-A, and EMIC (Table 3). These demonstrated that not only the C-SSS total score but also most C-SSS subscale scores were significantly correlated with TDQ, HAM-D, HAMA, and EMIC scores. This result suggests that the C-SSS has fair concurrent validity.

\section{Internal Consistency of Reliability}

The C-SSS displayed good reliability, with a Cronbach's $\alpha$ for the overall scale of 0.85 indicating strong internal consistency. Regarding the subscales, Cronbach's alphas ranged from 0.47 to 0.86 (Table 4). This result suggests that not only overall scale but every subscale has satisfactory internal consistency. The internal consistency remained stable (Cronbach's $\alpha$ coefficient ranged from 0.83 to 0.85 ) if any item was deleted. (Supplementary Table 2).

\section{Test-Retest Reliability}

We interviewed $50 \mathrm{HNC}$ patients twice to examine testretest reliability using the Pearson product-moment correlation coefficient for testing (Supplementary Table 3). The Pearson coefficient of the C-SSS overall scale was 0.655 , which indicates fair test-retest reliability. With regard to the C-SSS subscales, most of the Pearson coefficients ranged from 0.295 to $0.680(p<0.05)$. Only three items of the C-SSS demonstrated non-significant results, including item $6(r=0.189, p=0.188)$, item $4(r=0.190, p=0.186)$, and item $2(r=0.239, p=0.094)$.

\section{Inter-Rater Reliability}

One trained research assistant and one psychiatrist simultaneously conducted the C-SSS to interview $50 \mathrm{HNC}$ patients, and then the Pearson product-moment correlation coefficient was used to test inter-rater reliability (Supplementary Table 3). The Pearson coefficient of the C-SSS overall scale was 0.840 , which indicates satisfactory inter-rater reliability. Regarding C-SSS subscales, most of the Pearson coefficients ranged 0.362 from 0.826 $(p<0.05)$. Only item $14(r=0.234, p=0.103)$ of the C-SSS had a non-significant result.

\section{Discussion}

The aim of the present study was to adopt the SSS into a Chinese version and examine the psychometric properties of the resulting C-SSS. Our findings indicate that C-SSS is a reliable and valid instrument for evaluating HNC patients' perception of shame and stigma in the Taiwanese population.

In this study, Cronbach's $\alpha$ of the C-SSS was 0.85 , which is in an optimal range for internal consistency and consistent with the original SSS (Cronbach's $\alpha=0.93$ ). Furthermore, we also explored some psychometric properties that were not done in the original version of the SSS, including concurrent validity of the C-SSS with other validated measurements and test-retest and interrater reliability. ${ }^{17}$

Principal Component Analysis with Varimax rotation of the C-SSS revealed a five-factor structure. In the current study, four of the five reported factors replicating those in the original SSS proposed by Kissane, including factor 1 (Shame of Appearance), factor 2 (Regret), factor 3 (Social/ Speech Concern), and factor 5 (Sense of Stigma), which explained that a large proportion of the variability of the C-SSS was similar to those of the original SSS. ${ }^{17}$ However, factor 4 "Self-discrimination," was newly identified in the C-SSS, covering item 13 ("I have an urge to keep my cancer a secret"), item 10 ("I am embarrassed when I tell people about my diagnosis"), and item 9 ("I feel others consider me responsible for my cancer"). These items are more likely to imply the cultural differences between the Taiwanese and American sample, which may be due to the betel nut chewing habit that prevails in Taiwan, especially among blue-collar workers. ${ }^{33}$ The demographic data in this study also echoed the patterns of high proportions of construction and manufacturing occupations (24.5\%) and a high betel nut chewing rate (83.6\% have had the habit), findings that were consistent with previous epidemiologic Taiwanese data on HNC 
Table 2 Rotated Factor Loadings of the Shame and Stigma Scale Items

\begin{tabular}{|c|c|c|c|c|c|c|}
\hline $\begin{array}{l}\text { Item } \\
\text { Number }\end{array}$ & $\begin{array}{l}\text { Shame and Stigma Items in } \\
\text { Factor Order }\end{array}$ & $\begin{array}{l}\text { Factor I Shame } \\
\text { with Appearance }\end{array}$ & $\begin{array}{l}\text { Factor } 2 \\
\text { Regret }\end{array}$ & $\begin{array}{l}\text { Factor } 3 \text { Social/ } \\
\text { Speech Concerns }\end{array}$ & $\begin{array}{l}\text { Factor } 4 \text { Self- } \\
\text { Discrimination }\end{array}$ & $\begin{array}{l}\text { Factor } 5 \\
\text { Sense of } \\
\text { Stigma }\end{array}$ \\
\hline 2 & $\begin{array}{l}\text { I avoid looking at myself in the } \\
\text { mirror }\end{array}$ & 0.73 & -0.04 & -0.01 & 0.17 & -0.22 \\
\hline 3 & I am ashamed of my appearance & 0.68 & 0.12 & 0.12 & 0.18 & 0.09 \\
\hline 5 & I feel people stare at me & 0.63 & 0.01 & 0.02 & 0.05 & 0.35 \\
\hline $4(\mathrm{rev})$ & $\begin{array}{l}\text { I am happy with how my face or } \\
\text { neck looks }\end{array}$ & 0.63 & 0.10 & 0.06 & -0.33 & 0.08 \\
\hline 14 & $\begin{array}{l}\text { I sense that others feel strained } \\
\text { when around me }\end{array}$ & 0.55 & 0.15 & 0.24 & 0.31 & 0.11 \\
\hline 6 & $\begin{array}{l}\text { I avoid meeting people because of } \\
\text { my looks }\end{array}$ & 0.53 & 0.12 & 0.28 & 0.04 & 0.47 \\
\hline I (rev) & I like my appearance & 0.48 & 0.38 & 0.27 & -0.32 & 0.17 \\
\hline 8 & $\begin{array}{l}\text { I am distressed by the changes in } \\
\text { my face or neck }\end{array}$ & 0.47 & 0.25 & 0.40 & 0.04 & 0.21 \\
\hline 17 & $\begin{array}{l}\text { I feel sorry about things I have } \\
\text { done in the past }\end{array}$ & 0.16 & 0.88 & 0.13 & 0.02 & 0.04 \\
\hline 15 & I have a strong feeling of regret & 0.09 & 0.88 & 0.04 & 0.16 & 0.01 \\
\hline 16 & $\begin{array}{l}\text { I would do many things differently } \\
\text { if given a second chance }\end{array}$ & 0.09 & 0.81 & 0.14 & -0.04 & -0.01 \\
\hline 19 & I avoid talking with others & 0.05 & -0.02 & 0.77 & 0.27 & 0.13 \\
\hline 18 & $\begin{array}{l}\text { I am embarrassed by the change } \\
\text { in my voice }\end{array}$ & 0.26 & 0.11 & 0.76 & 0.17 & 0.00 \\
\hline $20(\mathrm{rev})$ & I am able to join conversations & 0.05 & 0.31 & 0.74 & -0.07 & 0.14 \\
\hline 13 & $\begin{array}{l}\text { I have an urge to keep my cancer } \\
\text { a secret }\end{array}$ & 0.06 & -0.17 & 0.11 & 0.77 & 0.01 \\
\hline 10 & $\begin{array}{l}\text { I am embarrassed when I tell } \\
\text { people my diagnosis }\end{array}$ & 0.20 & 0.23 & 0.15 & 0.69 & 0.22 \\
\hline 9 & $\begin{array}{l}\text { I feel others consider me } \\
\text { responsible for my cancer }\end{array}$ & -0.04 & 0.34 & 0.10 & 0.47 & 0.31 \\
\hline 12 & $\begin{array}{l}\text { People avoid me because of my } \\
\text { cancer }\end{array}$ & 0.05 & -0.00 & -0.02 & 0.20 & 0.80 \\
\hline $7(\mathrm{rev})$ & I enjoy going out in public & 0.12 & -0.05 & 0.34 & -0.03 & 0.49 \\
\hline 11 & $\begin{array}{l}\text { I feel ashamed for having } \\
\text { developed cancer }\end{array}$ & 0.34 & 0.21 & 0.18 & 0.38 & 0.46 \\
\hline
\end{tabular}

Notes: The factor loadings were extracted from the polychoric correlation matrix of the items using Principal Component Analysis with a Varimax rotation. Factor loadings in bold print indicate the subscale on which the item is scored. See Supplementary Table I for the Chinese version.

patients. ${ }^{10}$ As the association of betel nut chewing and $\mathrm{HNC}$ is widely known, $\mathrm{HNC}$ patients may tend to keep their illness secret, not disclose it, and feel that it is their own responsibility. Another cultural explanation for item 9 is the concept of "karma" in Taiwan, a term equated with fate and used in Ayurveda and Buddhism. ${ }^{34}$ Believing in karma 
Table 3 Pearson Product Moment Correlations $(n=153)$ of the Shame and Stigma Subscales with TDQ, HAMD, HAMA and EMIC

\begin{tabular}{|l|l|l|l|l|l|}
\hline Subscale & & TDQ & HAMD & HAMA & EMIC \\
\hline SSS Total score & $\mathrm{r}$ & $\begin{array}{l}0.53 I^{* *} \\
153\end{array}$ & $\begin{array}{l}0.52 I^{* *} \\
153\end{array}$ & $\begin{array}{l}0.509^{* *} \\
153\end{array}$ & $\begin{array}{l}0.532^{* *} \\
153\end{array}$ \\
\hline $\begin{array}{l}\text { Shame with } \\
\text { Appearance }\end{array}$ & $\mathrm{r}$ & $\begin{array}{l}0.43 \mathrm{I}^{* *} \\
153\end{array}$ & $\begin{array}{l}0.433^{* *} \\
153\end{array}$ & $\begin{array}{l}0.413^{* *} \\
153\end{array}$ & $\begin{array}{l}0.315^{* *} \\
153\end{array}$ \\
\hline Regret & $\mathrm{r}$ & $\begin{array}{l}0.390^{* *} \\
153\end{array}$ & $\begin{array}{l}0.337^{* *} \\
153\end{array}$ & $\begin{array}{l}0.339^{* *} \\
153\end{array}$ & $\begin{array}{l}0.203^{*} \\
153\end{array}$ \\
\hline $\begin{array}{l}\text { Social/Speech } \\
\text { Concerns }\end{array}$ & $\mathrm{r}$ & $\begin{array}{l}0.393^{* *} \\
153\end{array}$ & $\begin{array}{l}0.37 I^{* *} \\
153\end{array}$ & $\begin{array}{l}0.360^{* *} \\
153\end{array}$ & $\begin{array}{l}0.356^{* *} \\
153\end{array}$ \\
\hline Self-discrimination & $\mathrm{r}$ & $\begin{array}{l}0.155 \\
\mathrm{~N}\end{array}$ & $\begin{array}{l}0.218^{* *} \\
153\end{array}$ & $\begin{array}{l}0.196 \\
153\end{array}$ & $\begin{array}{l}0.55 I^{* *} \\
153\end{array}$ \\
\hline Sense of Stigma & $\mathrm{r}$ & $0.393^{* *}$ & $0.367^{* *}$ & $\begin{array}{l}0.393^{* *} \\
153\end{array}$ & $\begin{array}{l}0.516^{* *} \\
153\end{array}$ \\
\hline
\end{tabular}

Notes: $* p<0.05, * * p<0.01$

Abbreviations: TDQ, Taiwanese Depression Questionnaire; HAMD, Hamilton Depression Rating Scale; HAMA, Hamilton Anxiety Rating Scale; EMIC= Explanatory Model Interview Catalogue.

Table 4 Internal Consistency and Descriptive Statistics for the Shame \& Stigma Scale Total Score and Subscales

\begin{tabular}{|c|c|c|c|c|c|}
\hline & Scale & Alpha & Mean & SD & $\begin{array}{l}\text { Median } \\
\text { (IQR) }\end{array}$ \\
\hline $\begin{array}{l}\text { Total } \\
\text { scale }\end{array}$ & 20 items & 0.85 & 17.51 & 12.208 & $\begin{array}{l}15.00 \\
(9.00-22.00)\end{array}$ \\
\hline \multicolumn{6}{|c|}{ Subscales } \\
\hline & $\begin{array}{l}\text { Shame with } \\
\text { Appearance }\end{array}$ & 0.80 & 5.40 & 5.55 & $4.0(I-8.0)$ \\
\hline & Regret & 0.86 & 3.65 & 3.72 & $3.0(0-6.0)$ \\
\hline & $\begin{array}{l}\text { Social/Speech } \\
\text { Concerns }\end{array}$ & 0.74 & 2.88 & 3.20 & $2.0(0-5.0)$ \\
\hline & Self-discrimination & 0.60 & 3.23 & 2.99 & $\begin{array}{l}2.0 \\
(1.00-5.0)\end{array}$ \\
\hline & Sense of Stigma & 0.47 & 2.35 & 2.34 & $2.0(0-4.0)$ \\
\hline
\end{tabular}

Abbreviation: IQR, interquartile range.

produces a practical solution to medical dilemmas, including the etiology of an illness. ${ }^{34}$ In previous studies, patients have sometimes attributed their cancer to karma and suggested that suffering from cancer is their bad Karma, which further led to negative emotional responses and behaviors, as well as self-stigma. ${ }^{34-36}$

Compared with the original version of the SSS conducted among an American sample, we chose different tools to test the concurrent validity of C-SSS for measuring depression, anxiety, and illness-behaviors in our Taiwanese sample. TDQ, HAM-D, HAM-A, and EMIC were all validated and were even culture-specific for Taiwanese people. The total SSS score had positive correlations with the TDQ $(r=0.531, p<0.01)$, the HAM-D $(\mathrm{r}=0.521, \mathrm{p}<0.01)$, the HAM-A $(\mathrm{r}=0.509, \mathrm{p}<0.01)$, and the EMIC $(\mathrm{r}=0.532, \mathrm{p}<0.01)$. Most of the subscales (Shame of Appearance, Social/Speech Concerns, Sense of Stigma) were positively correlated with these validated measures, with the concurrent validity ranging from 0.315 to 0.516 . These findings indicate that those $\mathrm{HNC}$ patients who were more depressed or anxious may suffer from a higher level of shame and stigma. Such results are consistent with prior works on cancer patients' stigma, depression, and anxiety. Stigma was shown to have negative relationships between quality of life, anxiety, and depression in lung cancer patients. ${ }^{37}$ Another study reported that greater perceived stigma was related to greater depressive symptomatology ${ }^{38,39}$ Meanwhile, only Factor 4 Self-discrimination showed a moderate correlation with EMIC $(r=0.551, \mathrm{p}<0.01)$ and a low correlation with HAM-D ( $r=0.218, \mathrm{p}<0.01)$, but no significant correlation with the TDQ or HAM-A. Factor 4 "Selfdiscrimination", which was newly identified in this study, can be considered additional evidence to suggest that the EMIC is another useful instrument for exploring patients' stigma concepts among Taiwanese subjects.

The test-retest reliability of the C-SSS was found to be fair, with the Pearson coefficient of the total scale being $0.65(p<0.05)$, and most of the Pearson coefficients of the subscale ranged from 0.295 to $0.680(p<0.05)$. Only three SSS items demonstrated non-significant results, including item $6(r=0.189, p=0.188)$, item $4(r=0.190, p=0.186)$, and item $2(r=0.239, p=0.094)$. These three items were all relevant to "Shame of Appearance" (Factor 1). One explanation was that we conducted the test and retest with a 1-2-week interval during the inpatients' hospital stays; most of those patients underwent a surgical intervention in between. Their perception about their appearance may have changed postoperatively. Some people became more concerned after the operation when they actually looked in the mirror and saw the wounds or tracheotomy, while some people's anticipatory anxiety eased when they found that the wounds were not as large as they thought they would be.

Satisfactory inter-rater reliability was noted in the C-SSS overall scale with a Pearson coefficient of 0.84 . 
Regarding the subscales, most of the Pearson coefficients ranged from 0.362 to $0.826(\mathrm{p}<0.05)$. The only exception was item $14(\mathrm{r}=0.234, \mathrm{p}=0.103)$, which showed nonsignificance (Supplementary Table 3). Item 14 was "I sense that others feel strained when around me," which might be confused with "I feel strained when others are around me" in the Chinese language, thus causing inconsistent results from the language restriction. This reminds the interviewers to be more cautious when asking the item.

Another Chinese version of the scale about cancer stigma is the Chinese version of the cancer stigma scale, ${ }^{40}$ which measures attitudes towards cancer in noncancer patients. Compared to this scale, the strengths of our study are that we conducted clinical interviews rather than online surveys, focused on HNC patients themselves rather than the general population, and used factor analysis to demonstrate the structure results of different factors, including the "shame of appearance" factor, which was more specific to HNC patients.

\section{Study Limitations}

Our findings should be cautiously interpreted due to the following limitations. First, our sample compromised mostly male patients (95\%), while females only accounted for 5\%; however, according to local Taiwanese data, the gender distribution of HNC patients was $91.3 \%$ male and $8.7 \%$ female. ${ }^{10}$ In our study, the refusal rate was higher in female $(33.33 \%)$ than in male $(9.03 \%)$. This discrepancy may be caused by female patients being more likely to have self-stigma in traditional Taiwanese society, ${ }^{36}$ so that they tended not be recruited in our study to disclose their perceptions about illness and stigma. Additional larger samples and qualitative data on female HNC patients are warranted to further explore the issue. Second, this study was conducted at a single medical center, so the sample was homogenous and may limit the generalizability. Furthermore, though concurrent validity with TDQ, HAM-D, HAM-A, and EMIC was demonstrated, we did not evaluate divergent validity. Finally, the location of HNC may affect the patients' shame and stigma. Some HNCs were small in size and did not affect the patient's appearance and speech function after tumor excision. However, the influence of location of HNC on shame and stigma was not analyzed in this study.

\section{Clinical Implications}

In conclusion, this study showed that C-SSS had satisfactory psychometric properties and can be used as a reliable and valid instrument to assess perceptions of shame and stigma among HNC patients in Taiwan. Nevertheless, some cultural variations were elicited compared with the original English SSS version. Further research is warranted to confirm the validity of the C-SSS in other Chinese-speaking areas, confirm the factor structure, replicate results among larger samples, and explore the possible intervention for clinically reducing the shame and stigma of HNC patients.

\section{Acknowledgment}

First of all, we gratefully acknowledge the effort of Prof. Chih-Hsien Hsieh, who conduct the back-translation process of the questionnaire, and Prof. Cheng-Fang Yen and Prof. Cheng-Chung Chen, who provide expert feedback regarding the validity of the scale. This study was supported by a grant from the Kaohsiung Chang Gung Memorial Hospital, Taiwan (CMRPG1171). The funding agent has no role in study design, study performance, and the decision to submit the report. Dr. Yu Lee and Dr. Liang-Jen Wang are co-corresponding authors and contributed equally to this manuscript.

\section{Disclosure}

The authors report no conflicts of interest in this work.

\section{References}

1. Bray F, Ferlay J, Soerjomataram I, Siegel RL, Torre LA, Jemal A. Global cancer statistics 2018: GLOBOCAN estimates of incidence and mortality worldwide for 36 cancers in 185 countries. CA Cancer J Clin. 2018;68:394-424. doi:10.3322/caac.v68.6

2. Health Promotion Administration MoHaW, Taiwan. Taiwan Cancer RegistryTaiwan Cancer Registry Annual Report 2016. 2018.

3. Pezzuto F, Buonaguro L, Caponigro F, et al. Update on head and neck cancer: current knowledge on epidemiology, risk factors, molecular features and novel therapies. Oncology. 2015;89:125-136. doi:10.11 $59 / 000381717$

4. Guha N, Warnakulasuriya S, Vlaanderen J, Straif K. Betel quid chewing and the risk of oral and oropharyngeal cancers: a meta-analysis with implications for cancer control. Int $J$ Cancer. 2014; 135:1433-1443. doi:10.1002/ijc.v135.6

5. Sehlen S, Lenk M, Herschbach P, et al. Depressive symptoms during and after radiotherapy for head and neck cancer. Head Neck. 2003;25:1004-1018. doi:10.1002/hed.v25:12

6. Krebber AM, Buffart LM, Kleijn G, et al. Prevalence of depression in cancer patients: a meta-analysis of diagnostic interviews and self-report instruments. Psychooncology. 2014;23:121-130. doi:10.10 02/pon.3409

7. Kim SA, Roh JL, Lee SA, et al. Pretreatment depression as a prognostic indicator of survival and nutritional status in patients with head and neck cancer. Cancer. 2016;122:131-140. doi:10.1002/ cncr.29693

8. Rusch N, Angermeyer MC, Corrigan PW. Mental illness stigma: concepts, consequences, and initiatives to reduce stigma. Eur Psychiatry. 2005;20:529-539. doi:10.1016/j.eurpsy.2005.04.004 
9. Daher M. Cultural beliefs and values in cancer patients. Ann Oncol. 2012;23(Suppl 3):66-69. doi:10.1093/annonc/mds091

10. Hsu W-L, Yu K, Chiang C-J, Chen T-C, Wang C-P. Head and neck cancer incidence trends in Taiwan, $1980 \sim 2014$. Int J Head Neck Sci 2017.

11. Costa EF, Nogueira TE, de Souza Lima NC, Mendonca EF, Leles CR. A qualitative study of the dimensions of patients' perceptions of facial disfigurement after head and neck cancer surgery. Spec Care Dentist. 2014;34:114-121. doi:10.1111/scd.12039

12. Threader J, McCormack L. Cancer-related trauma, stigma and growth: the 'lived' experience of head and neck cancer. Eur J Cancer Care (Engl). 2016;25:157-169. doi:10.1111/ecc.12320

13. Dropkin MJ. Body image and quality of life after head and neck cancer surgery. Cancer Pract. 1999;7:309-313. doi:10.1046/j.15235394.1999.76006.x

14. Fingeret MC, Teo I, Goettsch K. Body image: a critical psychosocial issue for patients with head and neck cancer. Curr Oncol Rep. 2015;17:422. doi:10.1007/s11912-014-0422-0

15. Vickery LE, Latchford G, Hewison J, Bellew M, Feber T. The impact of head and neck cancer and facial disfigurement on the quality of life of patients and their partners. Head Neck. 2003;25:289-296. doi:10.1002/(ISSN)1097-0347

16. Katz MR, Irish JC, Devins GM, Rodin GM, Gullane PJ. Psychosocial adjustment in head and neck cancer: the impact of disfigurement, gender and social support. Head Neck. 2003;25:103-112. doi:10. 1002/(ISSN)1097-0347

17. Kissane DW, Patel SG, Baser RE, et al. Preliminary evaluation of the reliability and validity of the shame and stigma scale in head and neck cancer. Head Neck. 2013;35:172-183. doi:10.1002/hed.v35.2

18. Pirola WE, Paiva BSR, Barroso EM, Kissane DW, Serrano C, Paiva CE. Translation and cultural adaptation of the Shame and Stigma Scale (SSS) into Portuguese (Brazil) to evaluate patients with head and neck cancer. Braz J Otorhinolaryngol. 2017; 83:697-704. doi:10.1016/j.bjorl.2016.10.005

19. Lee Y, Yang MJ, Lai TJ, Chiu NM, Chau TT. Development of the Taiwanese depression questionnaire. Chang Gung Med J. 2000;23:688-694.

20. Lee Y, Lin PY, Hsu ST, Cing-Chi Y, Yang LC, Wen JK. Comparing the use of the Taiwanese depression questionnaire and beck depression inventory for screening depression in patients with chronic pain. Chang Gung Med J. 2008;31:369-377.

21. Lee Y, Wu YS, Chien CY, Fang FM, Hung CF. Use of the hospital anxiety and depression scale and the Taiwanese depression questionnaire for screening depression in head and neck cancer patients in Taiwan. Neuropsychiatr Dis Treat. 2016;12:2649-2657. doi:10.2147/ NDT.S112069

22. Hamilton M. A rating scale for depression. J Neurol Neurosurg Psychiatry. 1960;23:56-62. doi:10.1136/jnnp.23.1.56

23. Zheng YP, Zhao JP, Phillips M, et al. Validity and reliability of the Chinese Hamilton depression rating scale. $\mathrm{Br} J$ Psychiatry. 1988;152:660-664. doi:10.1192/bjp.152.5.660
24. Hamilton M. The assessment of anxiety states by rating. $\mathrm{Br} J \mathrm{Med}$ Psychol. 1959;32:50-55. doi:10.1111/papt.1959.32.issue-1

25. Maier W, Buller R, Philipp M, Heuser I. The Hamilton anxiety scale: reliability, validity and sensitivity to change in anxiety and depressive disorders. J Affect Disord. 1988;14:61-68. doi:10.1016/0165-0327 (88)90072-9

26. Weiss MG, Doongaji DR, Siddhartha S; The Explanatory Model Interview Catalogue (EMIC), et al. Contribution to cross-cultural research methods from a study of leprosy and mental health. $\mathrm{Br}$ J Psychiatry. 160;1992:819-830. doi:10.1192/bjp.160.6.819

27. van Brakel WH, Cataldo J, Grover S, et al. Out of the silos: identifying cross-cutting features of health-related stigma to advance measurement and intervention. BMC Med. 2019;17:13. doi:10.1186/ s12916-018-1245-x

28. Ackumey MM, Gyapong M, Pappoe M, Weiss MG. Help-seeking for pre-ulcer and ulcer conditions of Mycobacterium ulcerans disease (Buruli ulcer) in Ghana. Am J Trop Med Hyg. 2011;85:1106-1113. doi:10.4269/ajtmh.2011.11-0429

29. Weiss MG. Cultural epidemiology: an introduction and overview. Anthropol Med. 2001;8:5-29. doi:10.1080/13648470120070980

30. Bland JM, Altman DG. Cronbach's alpha. BMJ. 1997;314:572. doi:10.1136/bmj.314.7080.572

31. Koo TK, Li MY. A guideline of selecting and reporting intraclass correlation coefficients for reliability research. J Chiropr Med. 2016;15:155-163. doi:10.1016/j.jcm.2016.02.012

32. Hair JF, Black B, Babin B, Anderson RE, Tatham RL. Multivariate Data Analysis. 6th ed. Pearson; 1992.

33. Ko YC, Chiang TA, Chang SJ, Hsieh SF. Prevalence of betel quid chewing habit in Taiwan and related sociodemographic factors. J Oral Pathol Med. 1992;21:261-264. doi:10.1111/j.1600-0714.19 92.tb01007.x

34. Weiss MG. Karma and ayurveda. Anc Sci Life. 1987;6:129-134.

35. Chiang HH, Lu ZY. [Cultural perspectives of health and illness in the context of nursing]. Hu Li Za Zhi. 1996;43:42-48.

36. Tang PL, Mayer DK, Chou FH, Hsiao KY. The experience of cancer stigma in Taiwan: a qualitative study of female cancer patients. Arch Psychiatr Nurs. 2016;30:204-209. doi:10.1016/j.apnu.2015.08.015

37. Cataldo JK, Brodsky JL. Lung cancer stigma, anxiety, depression and symptom severity. Oncology. 2013;85:33-40. doi:10.1159/00035 0834

38. Gonzalez BD, Jacobsen PB. Depression in lung cancer patients: the role of perceived stigma. Psychooncology. 2012;21:239-246. doi: $10.1002 /$ pon. 1882

39. Ostroff JS, Riley KE, Shen MJ, Atkinson TM, Williamson TJ, Hamann HA. Lung cancer stigma and depression: validation of the lung cancer stigma inventory. Psychooncology. 2019;28:1011-1017. doi: $10.1002 /$ pon.5033

40. Ye X, Liu HY, Lu SR, Zhai Q, Yu B. Translation and validation of the Chinese version of the cancer stigma scale. $J$ Oncol Pharm Pract. 2018;25:1078155218802627.
Cancer Management and Research is an international, peer-reviewed open access journal focusing on cancer research and the optimal use of preventative and integrated treatment interventions to achieve improved outcomes, enhanced survival and quality of life for the cancer patient.
The manuscript management system is completely online and includes a very quick and fair peer-review system, which is all easy to use. Visit http://www.dovepress.com/testimonials.php to read real quotes from published authors. 